\title{
Phenacetin acts as a weak genotoxic compound preferentially in the kidney of DNA repair deficient Xpa mice
}

\author{
Mirjam Luijten ${ }^{a}{ }^{*}$, Ewoud N. Speksnijder ${ }^{a}$, Niels van Alphen ${ }^{a}$, Anja \\ Westerman $^{\mathrm{a}}{ }^{\text {, Siem H. Heisterkamp }}{ }^{\mathrm{b}}$, Jan van Benthem ${ }^{\mathrm{a}}$, Coen F. van \\ Kreijl $^{a}$, Rudolf B. Beems ${ }^{a}$ and Harry van Steeg ${ }^{a}$
}

\author{
aLaboratory of Toxicology, Pathology and Genetics, National Institute for Public \\ Health and the Environment (RIVM), P.O. Box 1, 3720 BA Bilthoven, The \\ Netherlands \\ ${ }^{\mathrm{b}}$ Centre for Information Technology and Methodology, National Institute for Public \\ Health and the Environment (RIVM), P.O. Box 1, 3720 BA Bilthoven, The \\ Netherlands
}

\begin{abstract}
Chronic use of phenacetin-containing analgesics has been associated with the development of renal cancer. To establish genotoxicity as a possible cause for the carcinogenic effect of phenacetin, we exposed wild type and DNA repair deficient

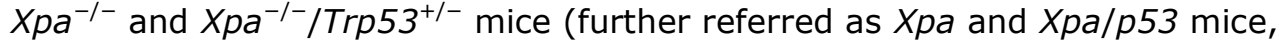
respectively), carrying a reporter lac $Z$ gene, to $0.75 \%(w / w)$ phenacetin mixed in feed. Xpa mice completely lack the nucleotide excision repair pathway, and as such they are sensitive to some classes of genotoxic compounds. Phenacetin exposure induced a significant increase of lacZ mutations in the kidney of both $X p a$ and $X p a / p 53$ mice. A minor response was found in liver, whereas no lacZ mutation induction was observed in the spleen of these animals. Interestingly, the observed phenacetin-induced mutant frequencies were higher in male than those found in female mice. This gender difference is probably due to a difference in metabolic rate. Phenacetin-induced mutations mainly consisted of point mutations rather than deletions. The mutational spectra in the kidney of treated WT and Xpa mice were quite similar. Taken together, these results demonstrate that the human carcinogen phenacetin acts as a weak genotoxic agent in an in vivo mouse model system.
\end{abstract}

\section{Introduction}

Up to the early 1980 s phenacetin was used as a common analgesic drug. Chronic use of phenacetin-containing analgesics has been associated with the development of renal cancer. The first report of a possible association between renal cancer and phenacetin use was published in 1965 [1]. Further reports and case-control studies also revealed an increased renal pelvis cancer risk in phenacetin abusers [2], [3], [4], [5], [6], [7], [8] and [9]. Some of these studies showed that the risk of renal pelvis cancer was increased three- to eight-fold as a consequence of long-term use of phenacetin-containing analgesics [10], [11], [12], [13], [14], [15] and [16]. Finally, in 1987, the International Agency for Research on Cancer concluded that limited epidemiologic evidence for phenacetin and sufficient evidence for analgesic mixtures containing phenacetin exist to regard phenacetin (or mixtures) to be carcinogenic to humans [17] and [18].

In vivo studies using B6C3F1 mice and Sprague-Dawley rats showed induction of renal cell and renal pelvic tumors after long term and high dose phenacetin 
Mutation Research/Fundamental and Molecular Mechanisms of Mutagenesis Volume 596, Issues 1-2 , 11 April 2006, Pages 143-150

exposure [19] and [20]. At the molecular level, however, it is still largely unknown through which mechanism phenacetin exerts its carcinogenic effect. Phenacetin gave positive results in the Ames assay in the presence of hamster liver S9, but not in the absence of metabolic activation [21] and [22].

Furthermore, phenacetin induced chromosomal aberrations in Chinese hamster cells in vitro [18] and a dose-dependent increase in the frequency of both DNA breaks and micro-nucleated cells in primary cultures of rat kidney cells [23].

Up to now it is still a matter of debate whether phenacetin causes renal pelvic tumors by virtue of its weak genotoxic feature, or through an indirect nongenotoxic mechanism initiated by renal papillary necrosis [13] and [24]. Renal papillary necrosis, often associated with chronic inflammation or bacterial infection, was found with high frequencies in subjects having phenacetinassociated cancer of the renal pelvis [13] and [24]. Chronic tissue damage, caused by phenacetin-induced renal papillary necrosis, has been suggested to explain the carcinogenic features of phenacetin [24] and [25].

In order to get more knowledge on the carcinogenic mode of action of phenacetin we used DNA repair-deficient Xpa mice [26] to study its possible genotoxicity. Previously, we and others showed that Xpa mice, completely lacking the nucleotide excision repair (NER) pathway, are highly cancer prone when exposed to genotoxic compounds like benzo[a]pyrene [27], [28] and [29] or 7,12dimethylbenz[a]anthracene [26]. In order to extend the sensitivity of the Xpa mouse model towards carcinogens, we crossed these DNA repair deficient mice with cancer prone $p 53^{+/-}$mice [30]. Xpa/p53 double knock-out mice appeared to respond to true human carcinogens in a highly discriminating way [31]. Not only genotoxic human carcinogens gave positive responses, but also human carcinogens, with other modes of action (i.e. non-genotoxic), were uncovered by this model.

The carcinogenic response of phenacetin in short-term carcinogenicity assays (39 weeks study) was previously tested in the $X p a$ and $X p a / p 53$ mouse models [31] and [32]. The results were considered as being equivocal since only one adenoma was found in the kidney of a treated $X p a / p 53$ female. However, multifocal karyomegaly was observed in all treated $X p a$ and $X p a / p 53$ mice (total 15 mice tested). By crossing both the Xpa and Xpa/p53 mice with pUR288 lacZ reporter mice and exposing them orally to phenacetin for a time period of maximal 12 weeks, we now demonstrate that phenacetin is a weak genotoxic analgesic drug, particularly in the kidney of DNA repair deficient Xpa mice.

\section{Materials and methods}

\subsection{Animals}

All mice used in the experiments were in a C57BL/6 genetic background. Xpa mice [26] were crossbred with $p 53^{+/-}$mice [30] in order to obtain $X p a / p 53$ double knockout mice. For mutant frequency analyses, WT, Xpa and Xpa/p53 mice were crossbred with C57BL/6 pUR288 lacZ reporter transgenic mice (line 60) [33]. To confirm genotypes, PCR analyses were performed as described previously [27]. All mice were housed in the animal facility in a climate-controlled room with a $12 \mathrm{~h}$ on/off light cycle. Tap water and feed were provided ad libitum.

\subsection{Genotoxicity study}

Six to nine-weeks old mice of all three genotypes (i.e. WT, Xpa and $X p a / p 53$ ) were treated for $0,4,8$, or 12 weeks with $0.75 \%$ phenacetin (Sigma, St. Louis, 
Mutation Research/Fundamental and Molecular Mechanisms of Mutagenesis Volume 596, Issues 1-2 , 11 April 2006, Pages 143-150

MO; CAS no. 62-44-2) mixed in the feed (Altromin, Lage, Germany). All treatment groups consisted of four males and four females. Body weight and food consumption were recorded weekly from the start of treatment until the terminal sacrifice.

Animal weights as well as various organ weights were determined at necropsy. Parts of isolated kidney, liver and spleen tissues were snap frozen in liquid $\mathrm{N}_{2}$ and remaining parts were fixed in $4 \%$ neutral buffered formaldehyde. Fixed tissues were embedded in paraffin wax, cut into $5 \mu \mathrm{m}$ sections, stained with hematoxylin and eosin, and evaluated by light microscopy.

Total genomic DNA was isolated as described previously [34]. Mutant frequencies were determined after rescuing lacZ-containing plasmids from genomic DNA. Detailed procedures for plasmid rescue have been described before [34]. In brief, pUR288 plasmids were rescued starting with 20-30 $\mu$ g genomic DNA using magnetic beads coated with lacZ/lacI fusion protein. Isolated plasmids were subsequently transfected into electrocompetent $E$. coli $C\left(\Delta / a c Z / g a l E^{-}\right)$. lacZ gene mutants were selected on plates containing the lactose analog phenyl $\beta$-Dgalactoside ( $\mathrm{pGal}$ ). Mutant frequencies were determined as the ratio of the number of colonies on the selective plates versus the number of total transformants rescued. Mutant frequencies were determined in duplo for each DNA sample.

\subsection{Mutation spectra}

Mutant colonies isolated from kidneys of male WT and Xpa mice were grown overnight in $3 \mathrm{ml}$ TY medium. Plasmids were mini-prepared using a commercial kit (Promega) and digested with AvaI and PstI. Digestion products were analyzed on $1 \%$ agarose gels in order to identify whether isolated mutant plasmids underwent size-changes. For each animal, about 20 different mutants were characterized. Mutants having no detectable insertion or deletion were entirely sequenced (base 1-3309 of the pUR288 plasmid). Sequence analyses were performed on an Applied Biosystems 3700 capillary sequencer using lacZ-specific primers [35]. The sequence reaction contained $1 \mu \mathrm{l}$ BigDye Terminator Reaction Kit, $200 \mathrm{mM}$ Tris, $5 \mathrm{mM} \mathrm{MgCl}, 0.16 \mu \mathrm{M}$ primer and 3-20 ng PCR product in a total volume of $20 \mu \mathrm{l}$. PCR reactions were carried out in a Perkin-Elmer 96 thermal cycler using the following conditions: 25 cycles of $96^{\circ} \mathrm{C}$ for $10 \mathrm{~s}, 50^{\circ} \mathrm{C}$ for $5 \mathrm{~s}$ and $60^{\circ} \mathrm{C}$ for $4 \mathrm{~min}$. Sequences were compared to the pUR288 sequence available at GenBank under the name SYNPUR288V.

\subsection{Statistical analyses}

Statistical analysis was performed using S-Plus 6.2 [36] and WinBugs v 1.4 .1 [37]. Mutant frequencies were analyzed using a linear mixed model with mouse as random effect. Fixed effects were taken as all three-way interactions of genotype, age, organ and sex with the exclusion of the three-way interaction genotype by age and by sex. Relevant contrasts were computed and tested using a normal distribution approach. Comparison of the proportion of point-mutations with size-change mutations (deletions and insertions) in the kidney of male WT and $X p a$ mice before and after phenacetin treatment was performed using Pearson's $X^{2}$ analysis. $P$-values were considered to be significant if smaller than 0.05 . The point mutation spectra were analyzed using a Bayesian approach, as described previously [38], using Monte Carlo Markov Chain (MCMC), 95\% posterior confidence intervals where computed from the MCMC simulated posterior distribution. The deviance information criterion (DIC) [37]) was used to fit the model optimally. 
Mutation Research/Fundamental and Molecular Mechanisms of Mutagenesis Volume 596, Issues 1-2 , 11 April 2006, Pages 143-150

\section{Results}

\subsection{Phenacetin is primarily genotoxic in the kidney of Xpa-deficient mice}

An in vivo gene mutation study with phenacetin was performed in order to investigate the underlying mechanism of karyomegaly observed in a previously published 39 weeks exposure study with DNA repair deficient $X p a$ and $X p a / p 53$ mice (see Table 1) [31] and [32]. Again in the present study, phenacetin treatment primarily induced karyomegaly in the proximal renal tubules of Xpa and $X p a / p 53$ mice, a typical example is shown in Fig. 1 . Strikingly, karyomegaly was found to be present in the current study within 4 weeks in a dose-related fashion and was again found to be more pronounced in male Xpa mice (not shown). Medullary (papillary) necrosis, frequently mentioned as a phenacetin-induced effect, was (still) absent at this time point.

Table 1.

Histopathological changes found in kidney of WT, Xpa and Xpa/p53 mice after 39 weeks of $0.75 \%$ phenacetin exposure

\begin{tabular}{|l|l|l|l|l|l|l|}
\hline & WT & Xpa & \multicolumn{2}{l|}{ Xpa/p53 } \\
\hline & Female & Male & Female & Male & Female & Male \\
\hline Number examined & 15 & 15 & 15 & 14 & 15 & 14 \\
\hline Multifocal karyomegaly & 0 & 0 & 15 & 14 & 15 & 14 \\
\hline Focal mononuclear cell infiltrate & 10 & 7 & 8 & 6 & 5 & 7 \\
\hline Basophilic tubules & 6 & 10 & 5 & 9 & 6 & 11 \\
\hline Increased brown pigment accumulation & 0 & 1 & 1 & 0 & 2 & 1 \\
\hline Nephrocalcinosis & 4 & 7 & 4 & 3 & 0 & 2 \\
\hline Focal proximal tubular hyperplasia & 0 & 0 & 0 & 2 & 0 & 1 \\
\hline Osseous metaplasia & 0 & 0 & 1 & 0 & 0 & 0 \\
\hline Renal tubular adenoma & 0 & 0 & 0 & 0 & 1 & 0 \\
\hline
\end{tabular}

Modified from Lina et al. [32].
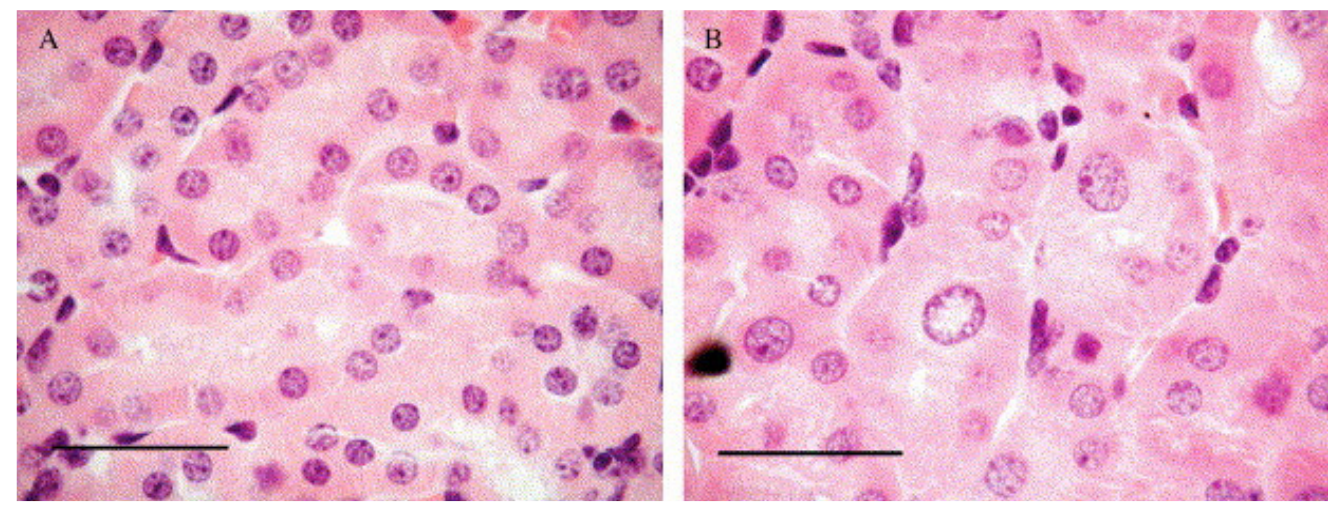

Fig. 1. Hematoxylin- and eosin-stained sections of the kidney of male $X p a / p 53$ mice, treated with $0.75 \%(w / w)$ phenacetin by feed for $0(A)$ and 12 weeks $(B)$. Karyomegaly, characterized by nuclear enlargement of renal cortical tubular cells, is clearly present after phenacetin treatment. The objective used was $64 \times$. Scale bars, $50 \mu \mathrm{m}$. 
Mutation Research/Fundamental and Molecular Mechanisms of Mutagenesis Volume 596, Issues 1-2 , 11 April 2006, Pages 143-150

LacZ mutant frequencies were determined in kidney, liver and spleen of WT, Xpa and $X p a / p 53$ mice (Fig. 2). Analysis of the mutant frequencies per organ revealed a significant increase of the lac $Z$ mutant frequencies after phenacetin treatment in the kidney of both $X p a$ and $X p a / p 53$ mice as compared to those found in the spleen $(P<0.001)$ or liver $(P<0.0001)$. The lac $Z$ mutant frequencies found in the kidney of $X p a$ and $X p a / p 53$ mice were also significantly increased by phenacetin treatment as compared to those found in the kidney of WT mice $(P<0.0001)$. A slight increase in lac $Z$ gene mutants was found in liver, although no differential response between genotypes and sexes was apparent. No genotoxic effect of phenacetin could be detected in the spleen.
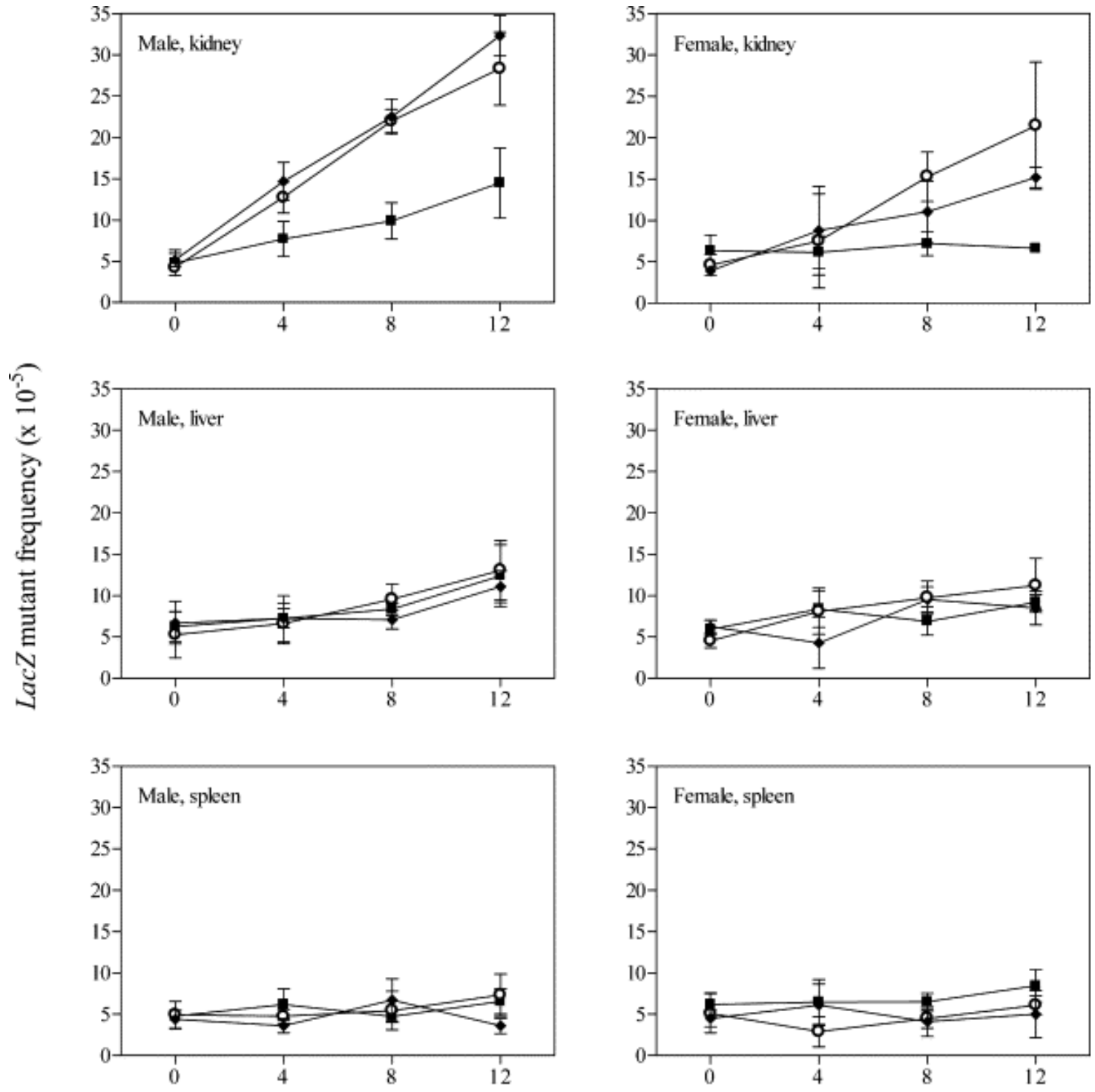

Phenacetin exposure (weeks)

Fig. 2. Average lac $Z$ mutant frequencies in kidney, liver and spleen of untreated and phenacetin-treated male and female WT, Xpa and Xpa/p53 lacZ transgenic mice. The mice ( $n=4$ per group or sex) with the indicated genotypes received $0.75 \%$ phenacetin by feed for a total period of 4,8 , or 12 weeks. Error bars indicate standard deviations of the means. Symbols: (๘) WT; (o) Xpa; (•) Xpa/p53. 
The mutant frequency in the kidney of phenacetin-treated WT and $X p a / p 53$ male mice was significantly higher than those found in female mice having the corresponding genotypes $(P<0.0001)$. In the kidney of Xpa mice, owing to large standard deviations, no such significant difference was observed between the two sexes. Finally, we did not find any $p 53$ gene-dose effect on lac $Z$ gene mutation induction.

\subsection{Mutation spectra}

LacZ mutants isolated from phenacetin-treated kidneys of WT and Xpa mice were collected for further analyses. We restricted the characterization of mutants to male mice only, since the observed phenacetin-induced mutant frequencies were most pronounced in males. Restriction enzyme digestion analyses were performed to elucidate whether the mutations induced by phenacetin were point mutations (no-change), gross deletions and/or other rearrangements mutation types (referred further as size-change mutations). As shown in Fig. 3, phenacetin treatment induced significantly more no-change (point) mutations rather than size-change mutations $(P<0.001)$ in both WT and Xpa mice. The ratio no-change mutations over size-change mutations in $X p a$ mice before and after phenacetin treatment did not significantly differ from that observed in WT mice.

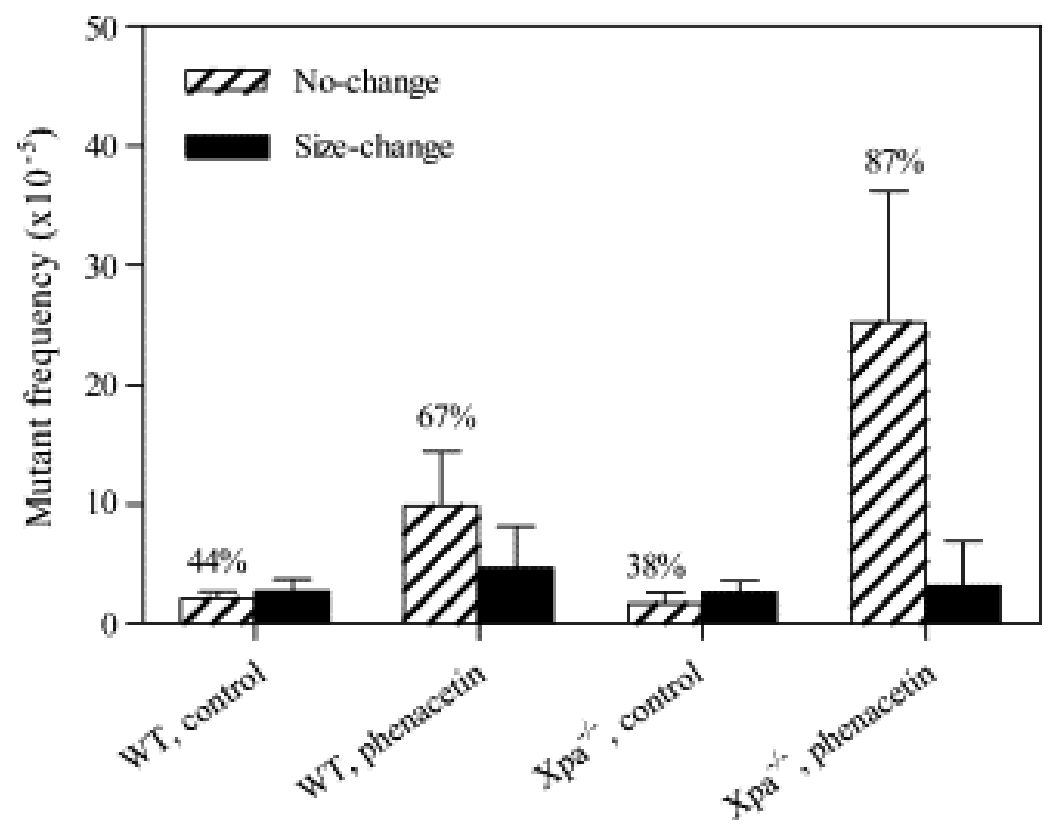

Fig. 3. Mean frequencies of no-change and size-change mutants in kidney of male WT and Xpa mice before and after phenacetin treatment. The different mutants (about 20 per individual animal) were selected as described in Section 2. Error bars indicate standard deviations of the means.

Several no-change mutants were further characterized. The lac $Z$ point mutational spectra found in the kidney of both control untreated and phenacetin-treated WT and Xpa mice are depicted in Fig. 4. The mutation spectra found in WT and Xpa mice were quite similar, except that the frequency in $X p a$ mice was found to be more robust. The point mutations found in both genotypes, either untreated or phenacetin-treated, were mainly GC to AT transitions and GC to TA transversions. The phenacetin-induced base substitutions along the lac $Z$ sequence were spread throughout the reporter gene (data not shown). A mutational hot spot (defined as $>5 \%$ of observed mutations at a single base pair) was not found. 
Mutation Research/Fundamental and Molecular Mechanisms of Mutagenesis Volume 596, Issues 1-2 , 11 April 2006, Pages 143-150
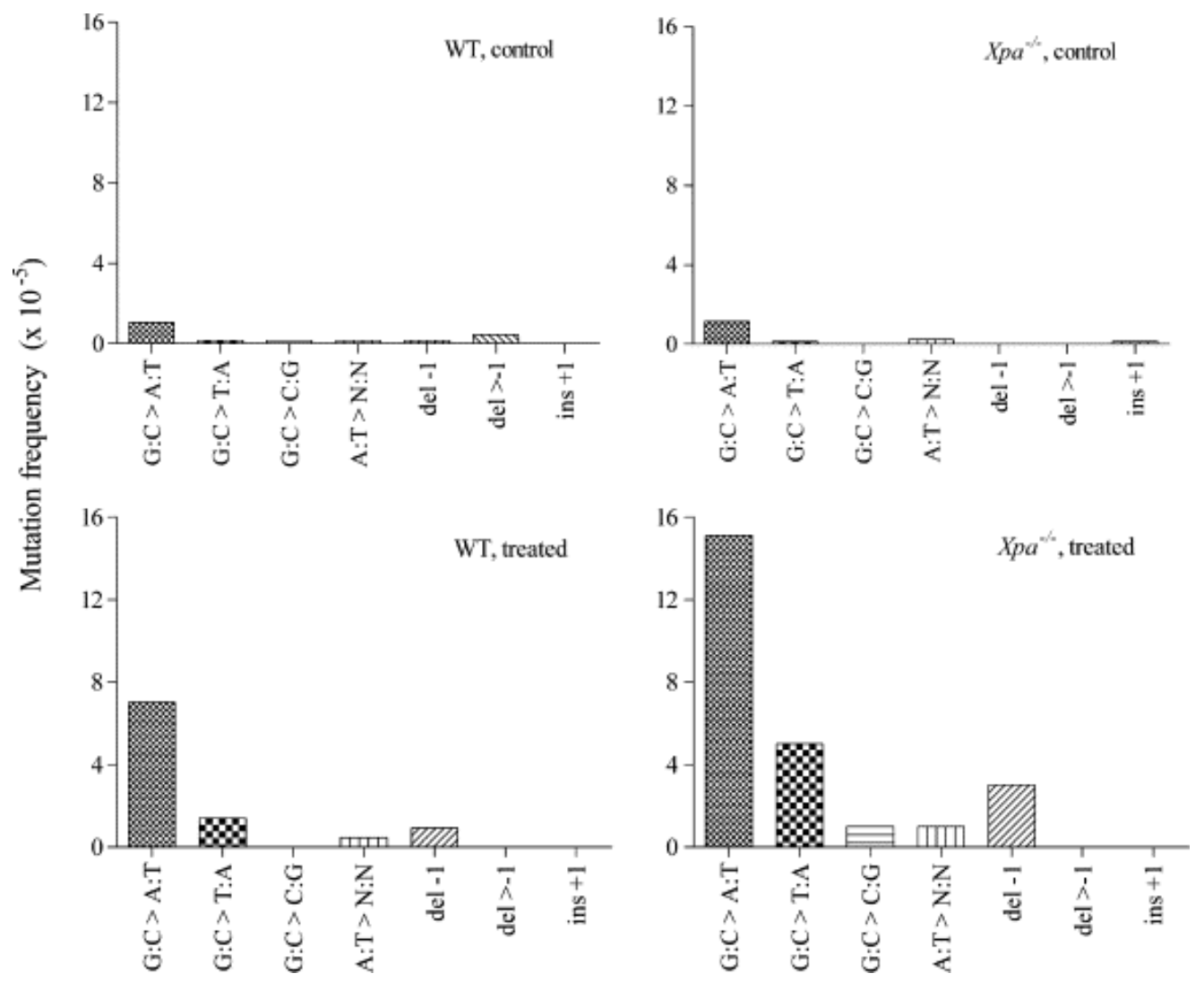

Fig. 4. Mutational spectra of kidney of male WT and Xpa mice, before and after phenacetin treatment. Sequence analyses were performed as described in Section 2. Bars indicate the frequency of each type of point mutation as indicated.

\section{Discussion}

In the present study we exposed WT, Xpa and $X p a / p 53$ mice to $0.75 \%(\mathrm{w} / \mathrm{w})$ phenacetin (mixed in feed) to study the possible genotoxic features of phenacetin in vivo. The data presented here provide evidence that phenacetin is a weak genotoxic carcinogen, since it appears to induce gene mutations specifically in NER-deficient $X p a$ and $X p a / p 53$ mice. The maximum increase in mutant frequency observed in the kidney of $X p a$ and $X p a / p 53$ mice after phenacetin treatment was about six-fold above background levels. This level is comparable to the mutant frequencies induced in $X p a$ mice after treatment with another weak genotoxic carcinogen, 2-amino-1-methyl-6-phenylimidazo[4,5-b]pyridine (PhIP) [39], but much lower than those induced by compounds like benzo[a]pyrene [27]. This indicates that the genotoxic feature of phenacetin is relatively weak, and as such difficult to detect in WT animals.

Although several metabolites of phenacetin have been described [40] and [41], biotransformation of phenacetin mainly involves $O$-deethylation to acetaminophen. Genotoxicity of phenacetin is unlikely to result from acetaminophen or its metabolites, since it has been extensively used as an analgesic drug, but was never associated with (renal) cancer formation. Other metabolites of phenacetin, like $N$-hydroxyphenetidine and $p$-nitrosophenetole, have been shown to be direct-acting mutagens [42] and [43] and may account for the observed (weak) genotoxicity of phenacetin in primarily NER deficient Xpa mice. As expected from the above these metabolites are not formed after 
Mutation Research/Fundamental and Molecular Mechanisms of Mutagenesis Volume 596, Issues 1-2 , 11 April 2006, Pages 143-150

acetaminophen administration and therefore, probably account for the absence of renal toxicity and/or tumorigenesis. Since phenacetin is mainly genotoxic in the kidney and to a lesser extent in the liver, this could mean that metabolites are rapidly transferred from the liver to the kidney and are further metabolized and/or eliminated from the kidney at slower rates.

In the current study, we found in all genotypes tested that the phenacetininduced mutant frequencies were higher in males than in females. CYP1A1/2 activity has been shown to play a role in the metabolic activation of phenacetin to the direct-acting mutagens $N$-hydroxyphenetidine and $p$-nitrosophenetole [40]. Male C57BL/6 mice have higher CYP1A2 levels than females [44], and as such this gender difference might underlie the observed difference in mutant frequency between males and females. The increased sensitivity of male mice is in line with the reported dose-related induction of renal cell tumors in male B6C3F1 mice in a long-term 2-year carcinogenicity study [20].

Next, we observed karyomegaly in the proximal renal tubules (Fig. 1) in both male and female Xpa mice; in male mice even in a dose dependent manner. Multifocal karyomegaly in the proximal renal tubules upon treatment with $0.75 \%$ phenacetin was also observed in the short-term carcinogenicity (39 weeks study) study [31] and [32]. We propose that karyomegaly is causally related to the genotoxic action of phenacetin (metabolites) and as such karyomegaly should be considered as an initial stage in tumor development, based on a genotoxic principle at least in DNA repair deficient Xpa mice. The association between proximal tubular karyomegaly and renal carcinogenesis has also been observed for other genotoxic compounds such as ochratoxin A and some heavy metals (lead, nickel, chromium and organic mercury) [45]. The observation in the present study that karyomegaly depends upon the DNA repair status further emphasizes its role in carcinogenesis. However, whether renal karyomegaly can be used in general as a consistent predictor of renal carcinogenicity remains to be established. Although it could be considered as a strong indication for DNA damage, other mechanisms leading to this change cannot be excluded at this time.

p53 haploinsufficiency did not result in a further increase in the lac $Z$ mutant frequency in the target tissues, which is in line with our previous reports on the effect of $p 53$ heterozygosity on the lac $Z$ mutant frequency in other target tissues [46] and [47]. Development of renal cell carcinomas is not clearly correlated with p53 mutations, as only $28 \%$ of these tumors carry such a mutation [48]. The relatively weak renal genotoxicity of phenacetin explains why only one tubular adenoma was found in the kidney of a Xpa/p53 female after 39 weeks of exposure [32]. It should also be noted that in a large number $X p a$ and $X p a / p 53$ mice, either control or treated, used in similar 39-week carcinogenicity studies never renal cell tumors were observed, indicating that these tumors are extremely rare in Xpa mice [31]. More pronounced phenacetin exposure, e.g. for 18 months (as in the rodent life time bio-assay), probably would have induced more tumors in the kidney of both Xpa and $X p a / p 53$ mice as compared to WT mice. Such an experiment would also possibly reveal a synergistic effect of $X p a$ and $p 53^{+/-}$deficiency, as we have demonstrated in several other studies using more potent genotoxic carcinogens [46] and [47].

In the kidney of male WT and Xpa mice, phenacetin treatment induced more point mutations than deletions or insertions. Above that the spectrum of the point mutations did not differ between WT and Xpa mice, but the response in Xpa mice was more robust. This observation is not unexpected since an altered mutation spectrum in Xpa mice would require an actively-transcribed gene. The lac $Z$ gene 
Mutation Research/Fundamental and Molecular Mechanisms of Mutagenesis Volume 596, Issues 1-2 , 11 April 2006, Pages 143-150

studied here is silent and therefore, all induced mutations originate from nontranscribed strands. Nevertheless, we provided evidence that phenacetin or its metabolites are substrate to the NER pathway and therefore, most likely genotoxic. In humans, the overall (weak) carcinogenic effect of phenacetin might be a combination of this genotoxic effect and renal papillary necrosis, which is most likely caused through another non-genotoxic mechanism.

\section{Acknowledgements}

We thank Coen Moolenbeek for the autopsies and the Central Animal Facility (RIVM-CDF) for their skillful biotechnical support. We are indebted to M. Dollé and E.M. Hoogervorst for critical reading of the manuscript and helpful discussions.

\section{References}

[1] N. Hultengren, C. Lagergren and A. Ljungqvist, Carcinoma of the renal pelvis in renal papillary necrosis, Acta Chir. Scand. 130 (1965), pp. 314-320.

[2] U. Bengtsson, L. Angervall, H. Ekman and L. Lehmann, Transitional cell tumors of the renal pelvis in analgesic abusers, Scand. J. Urol. Nephrol. 2 (1968), pp. 145-150.

[3] J.F. Mahony, B.G. Storey, R.C. Ibanez and J.H. Stewart, Analgesic abuse, renal parenchymal disease and carcinoma of the kidney or ureter, Aust. N.Z. J. Med. 7 (1977), pp. 463-469.

[4] L. Angervall, U. Bengtsson, C.G. Zetterlund and M. Zsigmond, Renal pelvic carcinoma in a Swedish district with abuse of a phenacetin-containing drug, Br. J. Urol. 41 (1969), pp. 401-405.

[5] S. Johansson, L. Angervall, U. Bengtsson and L. Wahlqvist, Uroepithelial tumors of the renal pelvis associated with abuse of phenacetin-containing analgesics, Cancer 33 (1974), pp. 743-753.

[6] W.R. Adam, J.K. Dawborn, C.G. Price, J. Riddell and H. Story, Anaplastic transitional-cell carcinoma of the renal pelvis in association with analgesic abuse, Med. J. Aust. 1 (1970), pp. 11081109.

[7] G. Hoybye and O.E. Nielsen, Renal pelvic carcinoma in phenacetin abusers, Scand. J. Urol. Nephrol. 5 (1971), pp. 190-192.

[8] T. Liu, G.W. Smith and J.T. Rankin, Renal pelvic tumor associated with analgesic abuse, Can. Med. Assoc. J. 107 (1972), p. 768.

[9] M. McCredie, J.M. Ford, J.S. Taylor and J.H. Stewart, Analgesics and cancer of the renal pelvis in New South Wales, Cancer 49 (1982), pp. 2617-2625.

[10] M. McCredie, J.H. Stewart, J.M. Ford and R.A. MacLennan, Phenacetin-containing analgesics and cancer of the bladder or renal pelvis in women, Br. J. Urol. 55 (1983), pp. 220-224.

[11] M. McCredie, J.H. Stewart and J.M. Ford, Analgesics and tobacco as risk factors for cancer of the ureter and renal pelvis, J. Urol. 130 (1983), pp. 28-30.

[12] J.K. McLaughlin, W.J. Blot, E.S. Mehl and J.F. Fraumeni Jr., Relation of analgesic use to renal cancer: population-based findings, Natl. Cancer Inst. Monogr. 69 (1985), pp. 217-222.

[13] M. McCredie, J.H. Stewart, J.J. Carter, J. Turner and J.F. Mahony, Phenacetin and papillary necrosis: independent risk factors for renal pelvic cancer, Kidney Int. 30 (1986), pp. 81-84.

[14] M. McCredie and J.H. Stewart, Does paracetamol cause urothelial cancer or renal papillary necrosis?, Nephron 49 (1988), pp. 296-300. 


\section{Mutation Research/Fundamental and Molecular Mechanisms of Mutagenesis Volume 596, Issues 1-2, 11 April 2006, Pages 143-150}

[15] O.M. Jensen, J.B. Knudsen, H. Tomasson and B.L. Sorensen, The Copenhagen case-control study of renal pelvis and ureter cancer: role of analgesics, Int. J. Cancer 44 (1989), pp. 965-968.

[16] M. McCredie, J.H. Stewart and N.E. Day, Different roles for phenacetin and paracetamol in cancer of the kidney and renal pelvis, Int. J. Cancer 53 (1993), pp. 245-249.

[17] IARC Monographs on the evaluation of the carcinogenic risks to humans: some pharmaceutical drugs, IARC Monographs 24, 1980, pp. 135-161.

[18] IARC Monographs on the evaluation of the carcinogenic risks to humans: overall evaluations of carcinogenicity: an updating of IARC Monographs volumes 1 to 42, IARC Monographs Suppl. 7, 1987, pp. 310-312.

[19] S.L. Johansson, Carcinogenicity of analgesics: long-term treatment of Sprague-Dawley rats with phenacetin, phenazone, caffeine and paracetamol (acetamidophen), Int. J. Cancer 27 (1981), pp. 521-529.

[20] K. Nakanishi, Y. Kurata, M. Oshima, S. Fukushima and N. Ito, Carcinogenicity of phenacetin: long-term feeding study in B6c3f1 mice, Int. J. Cancer 29 (1982), pp. 439-444.

[21] S. De Flora, P. Russo, M. Pala, G. Fassina, A. Zunino, C. Bennicelli, P. Zanacchi, A. Camoirano and S. Parodi, Assay of phenacetin genotoxicity using in vitro and in vivo test systems, J. Toxicol. Environ. Health 16 (1985), pp. 355-377.

[22] J.W. Oldham, R.F. Preston and J.D. Paulson, Mutagenicity testing of selected analgesics in Ames Salmonella strains, J. Appl. Toxicol. 6 (1986), pp. 237-243.

[23] L. Robbiano, R. Carrozzino, C.P. Puglia, C. Corbu and G. Brambilla, Correlation between induction of DNA fragmentation and micronuclei formation in kidney cells from rats and humans and tissuespecific carcinogenic activity, Toxicol. Appl. Pharmacol. 161 (1999), pp. 153-159.

[24] J.H. Stewart, J.B. Hobbs and M.R. McCredie, Morphologic evidence that analgesic-induced kidney pathology contributes to the progression of tumors of the renal pelvis, Cancer 86 (1999), pp. 15761582.

[25] P.P. Bringuier, M. McCredie, G. Sauter, M. Bilous, J. Stewart, M.J. Mihatsch, P. Kleihues and H. Ohgaki, Carcinomas of the renal pelvis associated with smoking and phenacetin abuse: p53 mutations and polymorphism of carcinogen-metabolizing enzymes, Int. J. Cancer 79 (1998), pp. 531-536.

[26] A. de Vries, C.T. van Oostrom, F.M. Hofhuis, P.M. Dortant, R.J. Berg, F.R. de Gruijl, P.W. Wester, C.F. van Kreijl, P.J. Capel, H. van Steeg and S.J. Verbeek, Increased susceptibility to ultraviolet-B and carcinogens of mice lacking the DNA excision repair gene XPA, Nature 377 (1995), pp. 169-173.

[27] A. de Vries, M.E. Dollé, J.L. Broekhof, J.J. Muller, E.D. Kroese, C.F. van Kreijl, P.J. Capel, J. Vijg and $\mathrm{H}$. van Steeg, Induction of DNA adducts and mutations in spleen, liver and lung of XPAdeficient/lacZ transgenic mice after oral treatment with benzo[a]pyrene: correlation with tumor development, Carcinogenesis 18 (1997), pp. 2327-2332.

[28] F. Ide, N. Iida, Y. Nakatsuru, H. Oda, K. Tanaka and T. Ishikawa, Mice deficient in the nucleotide excision repair gene XPA have elevated sensitivity to benzo[a]pyrene induction of lung tumors, Carcinogenesis 21 (2000), pp. 1263-1265.

[29] E.M. Hoogervorst, A. de Vries, R.B. Beems, C.T. van Oostrom, P.W. Wester, J.G. Vos, W. Bruins, M. Roodbergen, F.R. Cassee, J. Vijg, F.J. van Schooten and H. van Steeg, Combined oral benzo[a]pyrene and inhalatory ozone exposure have no effect on lung tumor development in DNA repair-deficient Xpa mice, Carcinogenesis 24 (2003), pp. 613-619.

[30] T. Jacks, L. Remington, B.O. Williams, E.M. Schmitt, S. Halachmi, R.T. Bronson and R.A. Weinberg, Tumor spectrum analysis in p53-mutant mice, Curr. Biol. 4 (1994), pp. 1-7.

[31] C.F. van Kreijl, P.A. McAnulty, R.B. Beems, A. Vynckier, H. van Steeg, R. Fransson-Steen, C.L. Alden, R. Forster, J.W. van der Laan and J. Vandenberghe, Xpa and Xpa/p53 ${ }^{+/-}$knockout mice: overview of available data, Toxicol. Pathol. 29 (2001) (Suppl.), pp. 117-127. 


\section{Mutation Research/Fundamental and Molecular Mechanisms of Mutagenesis Volume 596, Issues 1-2 , 11 April 2006, Pages 143-150}

[32] B.A. Lina, R.A. Woutersen, J.P. Bruijntjes, J. van Benthem, J.A. van den Berg, J. Monbaliu, B.J. Thoolen, R.B. Beems and C.F. van Kreijl, Evaluation of the Xpa-deficient transgenic mouse model for short-term carcinogenicity testing: 9-month studies with haloperidol, reserpine, phenacetin, and Dmannitol, Toxicol. Pathol. 32 (2004), pp. 192-201.

[33] M.E. Boerrigter, M.E. Dollé, H.J. Martus, J.A. Gossen and J. Vijg, Plasmid-based transgenic mouse model for studying in vivo mutations, Nature 377 (1995), pp. 657-659.

[34] M.E. Dollé, H.J. Martus, J.A. Gossen, M.E. Boerrigter and J. Vijg, Evaluation of a plasmid-based transgenic mouse model for detecting in vivo mutations, Mutagenesis 11 (1996), pp. 111-118.

[35] M.E. Dollé, H.J. Martus, M. Novak, N.J. van Orsouw and J. Vijg, Characterization of color mutants in lacZ plasmid-based transgenic mice, as detected by positive selection, Mutagenesis 14 (1999), pp. 287-293.

[36] Data Analysis Products Division, S-PLUS 2000 Guide to Statistics, MathSoft, Seattle (1999).

[37] D.J. Spiegelhalter, A. Thomas, N.G. Best and W.R. Gilks, BUGS: Bayesian Inference Using Gibbs Sampling, Version 0.5, MRC Biostatistics Unit, Cambridge (1996).

[38] M.E. Dollé, W.K. Snyder, D.B. Dunson and J. Vijg, Mutational fingerprints of aging, Nucleic Acids Res. 30 (2002), pp. 545-549.

[39] J.C. Klein, R.B. Beems, P.E. Zwart, M. Hamzink, G. Zomer, H. van Steeg and C.F. van Kreijl, Intestinal toxicity and carcinogenic potential of the food mutagen 2-amino-1-methyl-6-

phenylimidazo[4,5-b]pyridine (PhIP) in DNA repair deficient $\mathrm{XPA}^{-/-}$mice, Carcinogenesis 22 (2001), pp. 619-626.

[40] T. Nohmi, K. Mizokami, S. Kawano, M. Fukuhara and M. Ishidate Jr., Metabolic activation of phenacetin and phenetidine by several forms of cytochrome P-450 purified from liver microsomes of rats and hamsters, Jpn. J. Cancer Res. 78 (1987), pp. 153-161.

[41] S.R. Patierno, N.L. Lehman, B.E. Henderson and J.R. Landolph, Study of the ability of phenacetin, acetaminophen, and aspirin to induce cytotoxicity, mutation, and morphological transformation in C3H/10T1/2 clone 8 mouse embryo cells, Cancer Res. 49 (1989), pp. 1038-1044.

[42] A.M. Camus, M. Friesen, A. Croisy and H. Bartsch, Species-specific activation of phenacetin into bacterial mutagens by hamster liver enzymes and identification of $\mathrm{N}$-hydroxyphenacetin O-glucuronide as a promutagen in the urine, Cancer Res. 42 (1982), pp. 3201-3208.

[43] P.J. Wirth, P. Alewood, I. Calder and S.S. Thorgeirsson, Mutagenicity of N-hydroxy-2acetylaminofluorene and $\mathrm{N}$-hydroxyphenacetin and their respective deacetylated metabolites in nitroreductase deficient Salmonella TA98FR and TA100FR, Carcinogenesis 3 (1982), pp. 167-170.

[44] S. Löfgren, A.L. Hagbjörk, S. Ekman, R. Fransson-Steen and Y. Terelius, Metabolism of human cytochrome P450 marker substrates in mouse: a strain and gender comparison, Xenobiotica 34 (2004), pp. 811-834.

[45] K.N. Khan and C.L. Alden, Kidney. In: W. Haschek, C. Rousseaux and M.A. Wallig, Editors, Handbook of Toxicologic Pathology, Academic Press, San Diego (2002), pp. 255-336.

[46] C.T. van Oostrom, M. Boeve, B.J. van Den, A. de Vries, M.E. Dollé, R.B. Beems, C.F. van Kreijl, J. Vijg and $\mathrm{H}$. van Steeg, Effect of heterozygous loss of p53 on benzo[a]pyrene-induced mutations and tumors in DNA repair-deficient XPA mice, Environ. Mol. Mutagen. 34 (1999), pp. 124-130.

[47] E.M. Hoogervorst, C.T. van Oostrom, R.B. Beems, J. van Benthem, S. Gielis, J.P. Vermeulen, P.W. Wester, J.G. Vos, A. de Vries and H. van Steeg, p53 heterozygosity results in an increased 2acetylaminofluorene-induced urinary bladder but not liver tumor response in DNA repair-deficient Xpa mice, Cancer Res. 64 (2004), pp. 5118-5126.

[48] A. Tannapfel, H.A. Hahn, A. Katalinic, R.J. Fietkau, R. Kuhn and C.W. Wittekind, Incidence of apoptosis, cell proliferation and P53 expression in renal cell carcinomas, Anticancer Res. 17 (1997), pp. $1155-1162$ 